
www.globaljournalseries.com, Email: info@globaljournalseries.com

\title{
THE USE OF GEOELECTRICS IN THE STUDY OF A SHALLOW QUATERNARY ALLUVIAL AQUIFER IN YENAGOA, SOUTHERN NIGERIA
}

\section{K. S. OKIONGBO AND G. C. SORONNADI-ONONIWU}

(Received 05 May 2014; Revision Accepted 28 July 2014)

\begin{abstract}
Fifteen (15) electrical surveys (VES) were carried out and results used to delineate the shallow lithostratigraphic units and evaluate the electrical and hydrogeological characteristics of the aquifer zone of the alluvial deposits in Yenagoa metropolis and environs. The Schlumberger electrode configuration was adopted and maximum current electrode halfspacings $(A B / 2)$ ranged from 100 to $200 \mathrm{~m}$. The VES data were interpreted using $1 \mathrm{D}$ inversion technique software (1X1D, Interpex, USA). A maximum of four geoelectric layers were delineated and the aquifer is characterised by loose sand with resistivity ranging from $136.1-828.6 \Omega \mathrm{m}$ and thickness of $8.3-97.6 \mathrm{~m}$. The hydraulic conductivity $(K=$ $41.3 \mathrm{~m} /$ day) value measured in a reference borehole was combined with the normalized electrical conductivity $\left(\sigma^{1}\right)$ from a nearby vertical electrical sounding data. The resulting relation was interpreted with Dar Zarrouk parameters to infer the transmissivity variations at other vertical electrical sounding locations, where $K$ values are unknown. The results showed that the transmissivity is linearly related to the normalized transverse resistance and hydraulic conductivity is also linearly related with normalized aquifer resistivity. Transmissivity values in the aquifer vary from 342.8 to $4030.9 \mathrm{~m}^{2} /$ day, and hydraulic conductivity $K$ varies from $12.0-88.0 \mathrm{~m} /$ day throughout the study area.
\end{abstract}

KEYWORDS: Porosity, hydraulic conductivity, transmissivity, transverse resistance, Yenagoa

\section{INTRODUCTION}

Major sources of surface water supply to residents of Yenagoa before the creation of the Bayelsa state (Nigeria) were the Epie Creek and Ikoli River. Increase in population and industrial activity have resulted in the generation of substantial domestic wastes which are disposed of in uncontrolled manner within the Epie Creek and Ikoli River. This has led to a widespread pollution/contamination of the surface water sources. Presently, the only safe and reliable water resources is groundwater. Most residents depend largely on hand-dug wells and motorised boreholes for their domestic water supply.

The shallow alluvial aquifer supplies domestic, municipal and industrial water to Yenagoa and environs, and is an important economic resource for the State. Because a thorough understanding of the hydrogeologic framework of this aquifer is fundamental to the evaluation and management of the groundwater system, it is necessary to have as much information as possible relating to its lateral and vertical extent, its continuity and structure, possible sources of recharge, degree of saturation, chemical quality of the groundwater and, the formation characteristics. The latter have been determined to some extent in the area by geological mapping, drilling of boreholes and examination of cores, and by pumping tests. This paper summarises recent work carried out in the Geophysics Unit of the Department of Physics, Niger Delta University, on the use of resistivity method to characterise shallow aquifers.

Geoelectric surveys using vertical electrical sounding (VES) are well suited to the investigation of alluvial aquifers where various lithologic units often have large resistivity contrasts. Surface geophysical methods are non invasive and cost-effective alternatives for obtaining information on aquifer characteristics (Frohlich and Urish, 2002). On the other hand, borehole data are necessary in an aquifer study, but very expensive if they are the only means of investigation. Besides, boreholes are invasive and can alter the properties of an aquifer if they are spaced too closely to each other. Also, information from a borehole is laterally very constrained, therefore to obtain satisfactory results, both methods are combined. In this study, vertical electrical sounding data in combination with geological data have been used to delineate the shallow lithostratigraphic units and evaluate the geophysical hydrogeological characteristics of the aquifer zone in several locations in the study area.

\section{DESCRIPTION OF STUDY AREA AND GEOLOGY}

The study area (Yenagoa and environs) is part of the Coastal Sedimentary Basin of Southern Nigeria. It is bounded by Latitudes $04^{\circ} 23.3^{\prime}$ and $04^{\circ} 38.2^{\prime}$ North and Longitudes $006^{\circ} 05^{\prime}$ and $006^{\circ} 40^{\prime}$ East (Fig. 1) and has an aerial extent of about $70 \mathrm{~km}^{2}$. It is a typical deltaic plain with a monotonous and essentially flat topography drained and criss-crossed by network of rivers, creeks and oxbow lakes e.g Kolo Creek, Epie Creek, Yenagoa

K. S. Okiongbo, Geophysics Unit, Department of Physics, Niger Delta University, Wilberforce Island, Bayelsa State, Nigeria

G. C. Soronnadi-Ononiwu, Department of Geology, Niger Delta University, Wilberforce Island, Bayelsa State, Nigeria 
and Nun River, etc. They all form a network which empties into the Atlantic Ocean through the Nun River Estuary. The low-lying alluvial plains are characterised by vegetation consisting of various trees, including palm trees and a variety of shrubs. The study area has a tropical climate with two distinct seasons, wet (April October) and dry (November - March). Land use within the area is primarily agricultural. The fertile land produces abundant yields of corn, cassava, plantain etc and provides excellent pasture for cattle. Water is tapped from the shallow aquifer. This same aquifer provides municipal and industrial water to the area, as well as domestic water to local inhabitants. Okiongbo and Douglas (2013) reported that the cations and anions analysed from groundwater samples in the area are low and well within the standard (WHO, 2004) limits for safe drinking specified for drinking and other purposes with the exception of iron in about $21 \%$ of the samples with concentration levels exceeding the permissible limit.

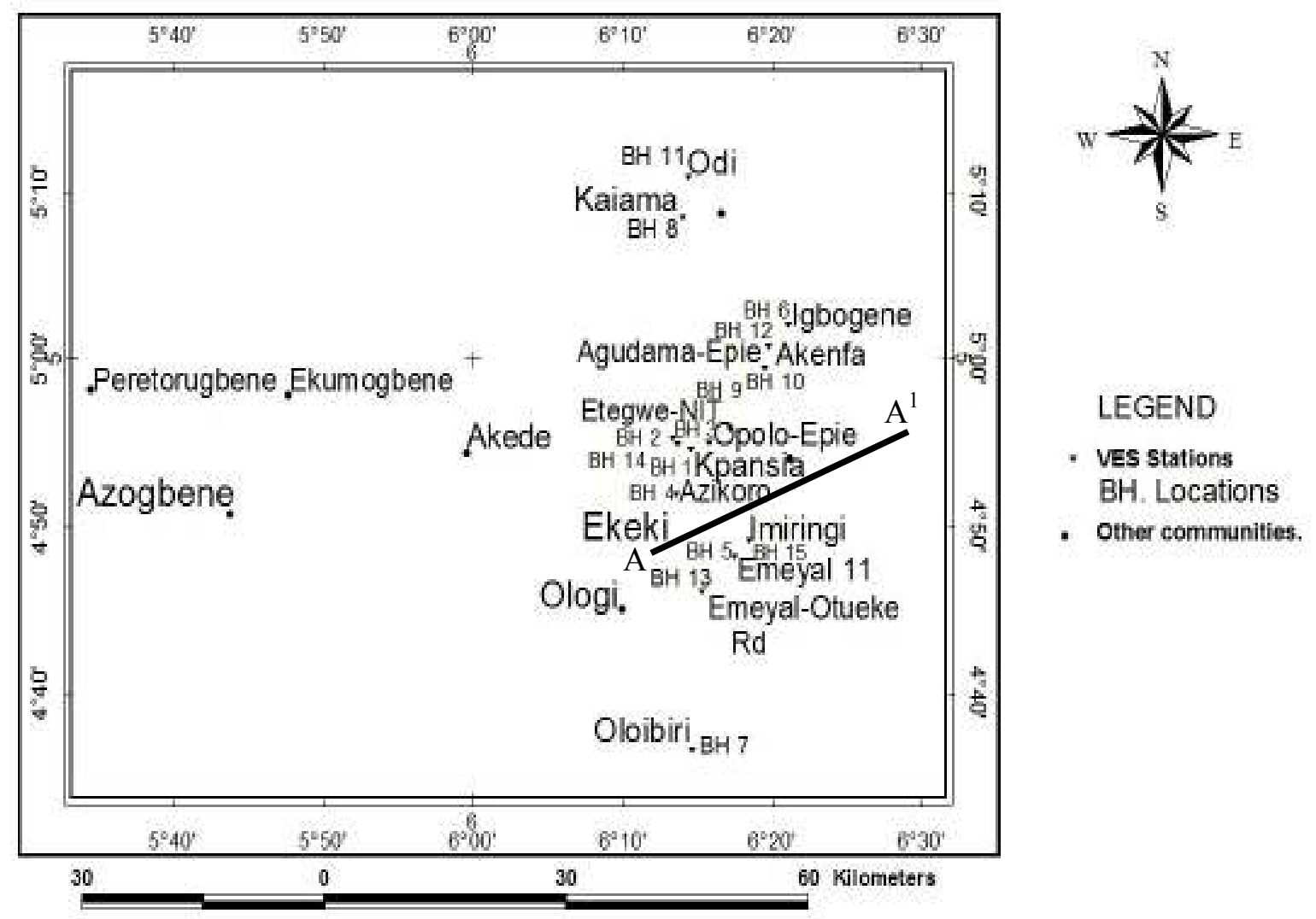

Fig. 1: Map of Study Area showing VES and Borehole Locations

The general geology of the Niger Delta consists of various types of Quaternary deposits overlying thick Tertiary sandy and clayey deltaic deposits. Three main lithostratigraphic units have been identified (Short and Stauble, 1976) in the Niger Delta. From bottom to top they are Akata, Agbada and Benin Formations. Detailed studies of the Quaternary deposits of the Niger Delta by Allen (1965) revealed that the sediments were deposited under the influence of fluctuating Pleistocene eustatic sea levels. The Coastal Plain Sands contain the aquifer serving most of the population of Bayelsa State. Groundwater in the Coastal Plain Sands occurs mainly under phreatic (unconfined) conditions. The lithology of this formation is dominated by loose sands (fine, medium and coarse grained sands), while gravel and pebble occur as minor components. Thin clay horizons and lenses create discontinuities in the vertical and lateral continuity of the porous sands and gravel. This condition results in the presence of local perched aquifers. The unconfined aquifer has high water yielding potential.

\section{MATERIALS AND METHOD}

Fifteen (15) vertical electrical sounding (VES) stations were carried out across the study area (Fig 1). Maximum current electrode half-spacings $(A B / 2)$ ranged from 100 to $200 \mathrm{~m}$. The instrument used was an Abem Terrameter SAS 3000, a digital self averaging instrument for DC resistivity work. The positions and surface elevations of VES locations were also recorded during survey with a GPS receiver. Computed apparent resistivity values were plotted against half-current spacing $(A B / 2)$ on log-log scale (Fig. 2). The data obtained was later subjected to computer assisted iterative interpretation using a 1-D inversion technique software (1X1D, Interpex, USA). Lithologic data of existing boreholes in the study area were used to constrain the VES interpretations. The model parameters for each VES station are presented in Table 1. All VES stations were conducted close to pre-existing water boreholes. Water samples collected from these boreholes were used for the determination of water 
resistivity. Pump test was carried out on borehole at Kpansia close to VES stations 2 to determine the hydraulic conductivity.
From model parameters of the VES data, the Dar-Zarrouk parameters, that is, the transverse unit resistance $(R)$ and the longitudinal conductance $(C)$, was determined as follows:

$C=\frac{h}{\rho}$ and $R=\rho \times h$

where $\mathrm{h}$ is the thickness of the aquifer and $\rho$ and is the resistivity of the aquifer. Transmissivity $T$, is related to hydraulic conductivity, $K$, as

$\mathrm{T}=\mathrm{Kh}$

Niwas and Singhal (1981) determined analytically the relationship between transmissivity and transverse resistance on the one hand and the transmissivity and longitudinal conductance on the other. Niwas and Singhal (1981) suggested that if a prism has isotropic and homogenous aquifer material having a unit cross sectional area and thickness $h$, the hydraulic and electric parameters can be combined to give the following equation:

$\begin{aligned} T & =K \sigma R=\frac{K C}{\sigma} \\ \sigma & =\frac{1}{\rho} \\ R & =h \times \rho \\ C & =\frac{h}{\rho} \text { or } C=h \times \sigma\end{aligned}$

Where

$T=$ Aquifer transmissivity $\left(\mathrm{m}^{2} / \mathrm{s}\right)$

$K=$ Hydraulic conductivity $(\mathrm{m} / \mathrm{s})$

$\sigma=$ Electrical conductivity $(\mu \mathrm{S} / \mathrm{cm})$

$\rho=$ Resistivity of the medium (ohm-m)

$R=$ Transverse resistance of the aquifer $\left(\right.$ ohm $\left.-\mathrm{m}^{2}\right)$

$C=$ Longitudinal conductance $\left(\mathrm{ohm}^{-1}\right)$

Equation 3 assumes that the change in aquifer resistivity is due to the changes in aquifer material (excluding the rock matrix) and the tortuosity of the interconnected pores (Millet, 1947). However, it is presumed that gross chemical quality remains relatively uniform. In areas of similar geological conditions and water quality, the product Ko remains fairly constant (Niwas and Singhal, 1981). Thus knowing $K$ values for existing boreholes and $\sigma$ values extracted from the sounding interpretation of the aquifer at different points, transmissivity can be determined (Louis et al 2004). Niwas and Singhal (1985) modified these relationships by using a modified aquifer resistivity, instead of aquifer resistivity which is known as normalized aquifer resistivity (Kosinski and Kelly, 1981) to incorporate variations in the quality of groundwater. However, the modification factor is always the ratio of the average pore water resistivity $\left(\overline{\rho_{w}}\right)$ and the pore water resistance $\left(\rho_{\mathrm{w}}\right)$ at the measuring point. Thus, equation 3 can be written as:

$$
\begin{gathered}
T=K \sigma^{1} R^{1} \\
\sigma^{1}=\sigma \frac{\rho_{w}}{\overline{\rho_{w}}} \\
R^{1}=R \frac{\overline{\rho_{w}}}{\rho_{w}}
\end{gathered}
$$

Where, $\sigma^{1}=$ normalized electrical conductivity and $R^{1}=$ normalized transverse resistance of the aquifer. The product $\mathrm{K}^{1}$ was assumed to be constant at a reference point of the aquifer and therefore known. Thus, the corollary of Eq. 3 can be written as:

$K=\alpha \rho^{1}$

Where $\alpha$ is equal to the product of $K \sigma^{1}$. The parameter $\rho^{1}$ is the modified aquifer resistivity that is defined as:

$\rho^{1}=\rho \frac{\overline{\rho_{w}}}{\rho_{w}}$

where $\rho, \rho_{w}$ and $\overline{\rho_{w}}$ were defined earlier.

The $K \sigma^{1}$ constant has been calculated at borehole 2 by using the $K$ value from the pumping test and the $\sigma$ value from the nearby sounding station. This constant was combined with the normalized transverse resistances $\left(R^{1}\right)$ at the rest of the stations to investigate the transmissivity variations throughout the study area. As the $K \sigma^{1}$ value is constant, 
transmissivity values are expected to vary from site to site depending on the change in the normalized transverse resistance. Hydraulic conductivity was computed using Eq. 5. Table 2 gives a summary of the interpreted results of the VES, resistivities, hydraulic conductivities, and transmissivities. An average value for the pore water resistivity $\left(\rho_{w}\right)$ was determined for the purpose of calculating the normalized aquifer resistivity $\left(\rho^{1}\right)$ and transverse resistance $\left(R^{1}\right)$.

RESULTS AND DISCUSSION

The sounding results reflect, geoelectrically, three and four layer curves of the $\mathrm{H}-, \mathrm{KH}-$, and HK-types (Fig. 2).
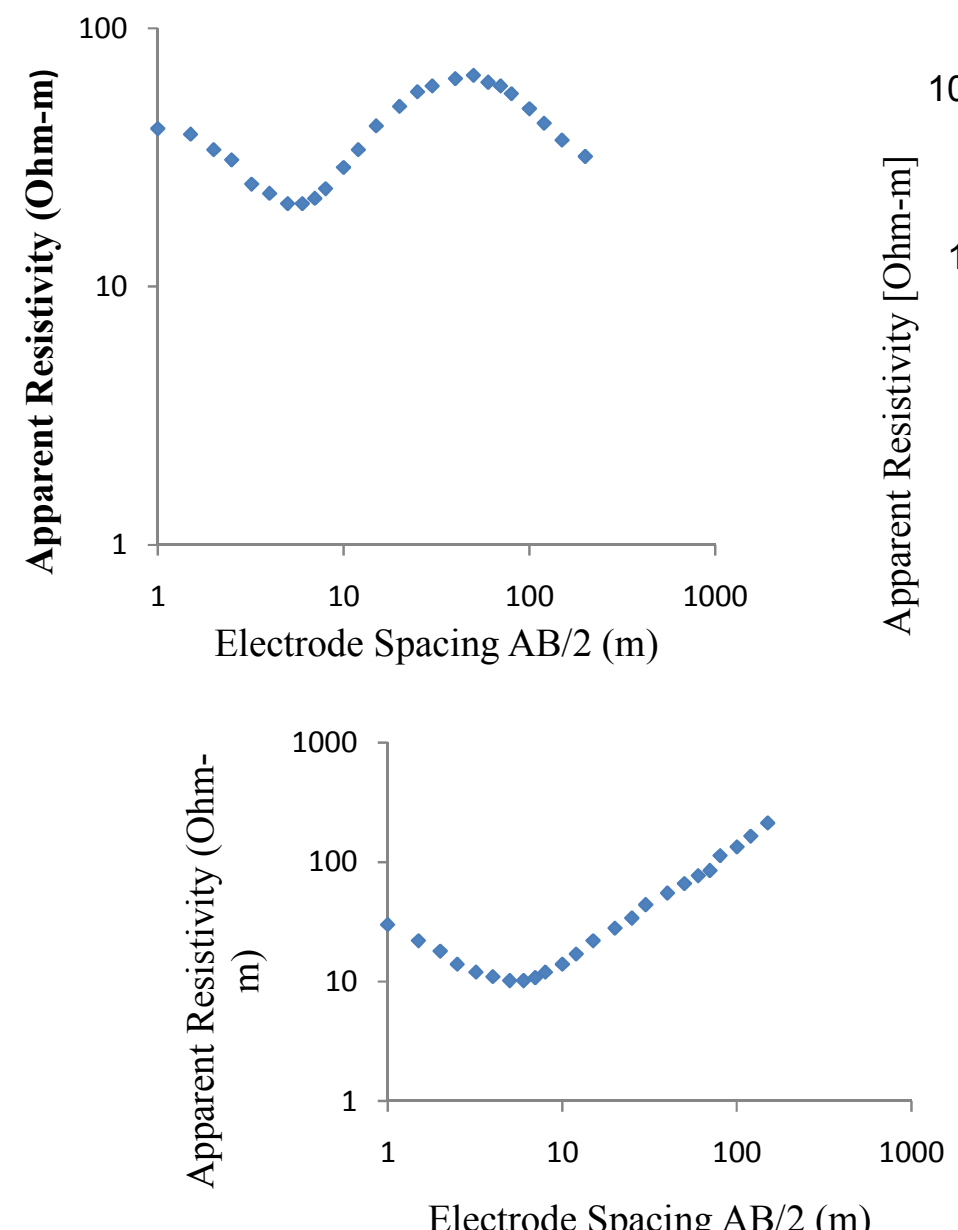

Electrode Spacing AB/2 (m)

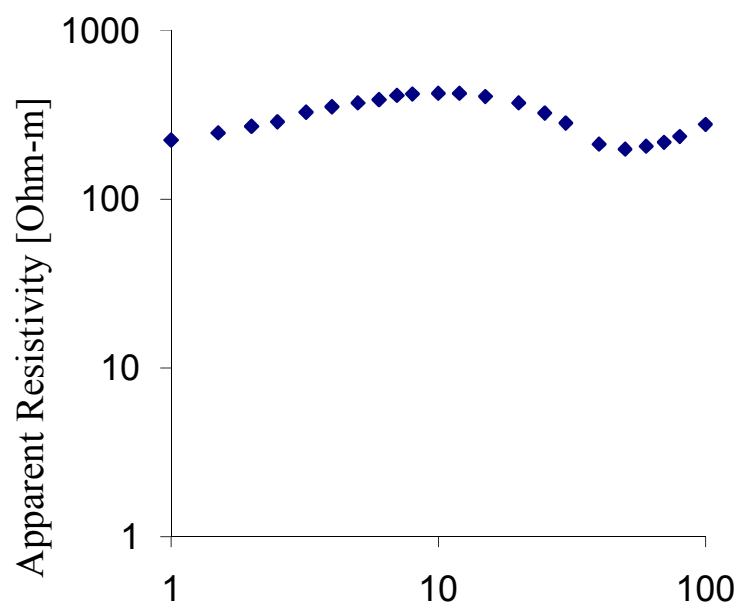

Electrode Spacing AB/2 [m]

Fig. 2. Geoelectric sounding curves at VES stations 3,8 and 11.

The geoelectric cross section Fig. 3 is based on the interpreted VES data. The geoelectric section illustrate the sedimentary succession, lateral, and vertical resistivity that reflects the lithologic changes of the different layers. The hydrostratigraphic section in the study area consists of a top layer composed of soils, sandy silts and clays, with some humus (Amajor, 1991). The thickness of this surface layer ranges between $0.5-$ $3.5 \mathrm{~m}$, and the resistivity depends on the soil moisture

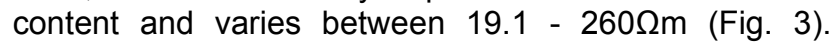




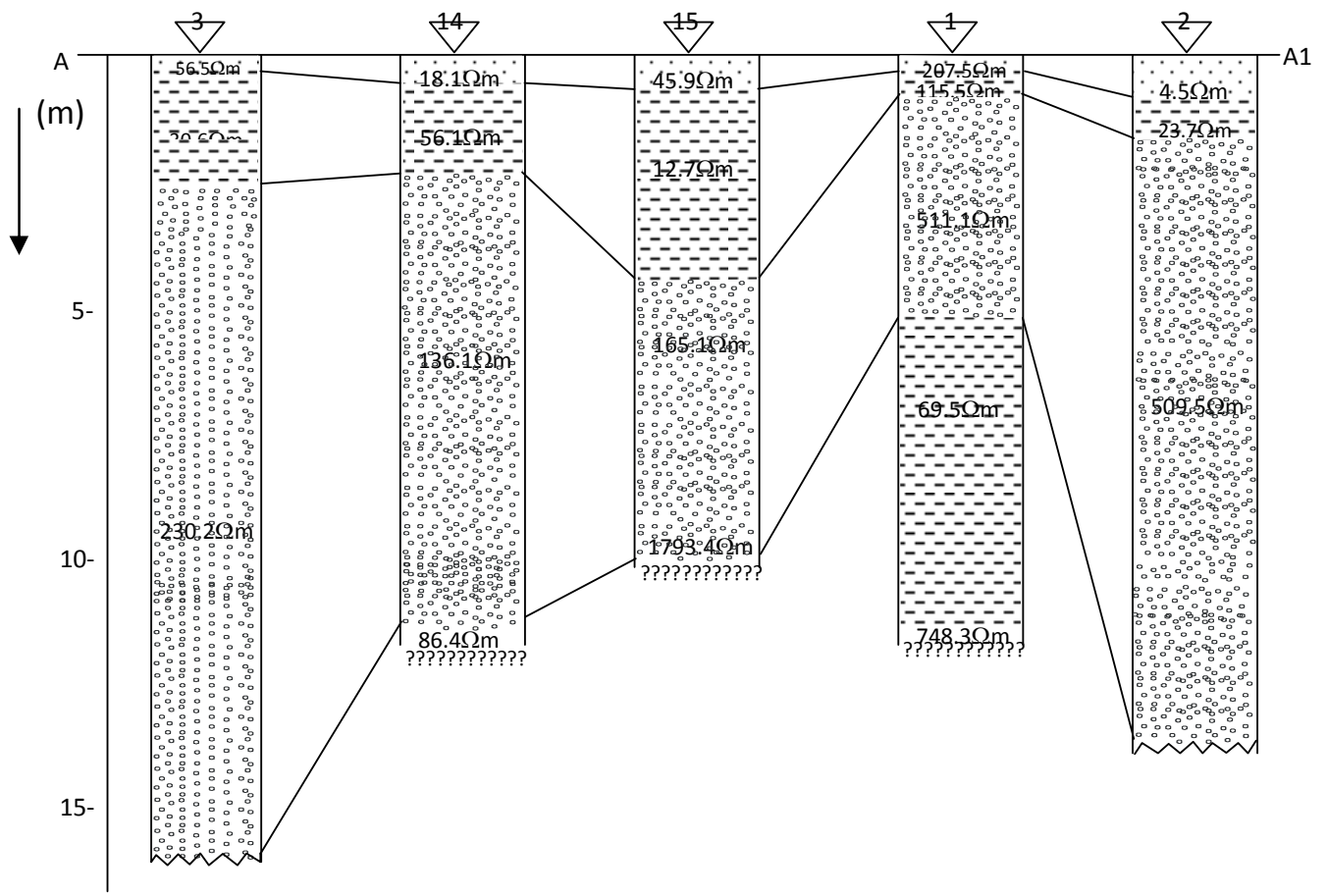

Fig. 3: Schematic geoelectrical section $A A^{1}$

The second layer is a clay unit. The true resistivity of this layer range from $12.7-74 \Omega \mathrm{m}$. More than half of the values are above $15 \Omega \mathrm{m}$ which strongly suggests that the unit in most areas is a mix of coarser-grained clastics and very fine-grained sediment (Ayers, 1989).

Table 1: Summary of results from computer modelling for all sounding stations

\begin{tabular}{l|llll|llllll}
\hline VES & \multicolumn{4}{|c|}{ Layer Thickness } & \multicolumn{3}{c}{ Layer Resistivity } & \multicolumn{3}{c}{ RMS } \\
No & 1 & 2 & 3 & 4 & 1 & 2 & 3 & 4 & 5 & Error \\
\hline 1 & 0.6 & 1.5 & 8.3 & 17.7 & 207.5 & 115.1 & 511.1 & 69.5 & 748.3 & 1.1738 \\
2 & 2.1 & 2.5 & 47.5 & - & 4.5 & 23.7 & 509.5 & 2945.1 & - & 4.4465 \\
3 & 0.5 & 4.7 & 97.6 & - & 56.5 & 30.6 & 230.2 & 126.4 & - & 3.7510 \\
4 & 0.7 & 5.7 & 17.9 & - & 146.3 & 56.9 & 303.6 & 1412.5 & - & 2.4742 \\
5 & 0.5 & 6.3 & 81.2 & - & 239.5 & 47.1 & 376.1 & 375.2 & - & 4.0024 \\
6 & 0.6 & 1.4 & 5.6 & 57.9 & 50.4 & 52.5 & 9.6 & 441.1 & 100.8 & 2.586 \\
7 & 1.3 & 25.5 & 22.8 & - & 221.8 & 71.7 & 293 & 9516 & - & 3.8467 \\
8 & 1.1 & 11.1 & 29.4 & - & 214.4 & 480.9 & 110.6 & 1203.5 & - & 2.5298 \\
9 & 2.5 & 1.8 & 30 & 35.9 & 56.1 & 80.2 & 191.6 & 44.2 & 416.7 & 3.2951 \\
10 & 2.8 & 5.6 & 21.7 & - & 35.9 & 131.2 & 315.5 & 74.9 & - & 3.0279 \\
11 & 0.8 & 6.9 & 17.7 & - & 33.1 & 8.4 & 273.9 & 2092.7 & - & 3.9026 \\
12 & 1.4 & 13.2 & 25.6 & - & 72.1 & 14.6 & 663.5 & 148.9 & - & 2.7507 \\
13 & 0.7 & 4.7 & 17.6 & - & 111.4 & 36.6 & 828.6 & 21009 & - & 4.4293 \\
14 & 1.2 & 4.4 & 24.3 & - & 18.1 & 56.1 & 136.1 & 86.4 & - & 5.3410 \\
15 & 1.5 & 9.6 & 13.7 & - & 45.9 & 12.7 & 165.1 & 1793.4 & - & 5.2594 \\
\hline
\end{tabular}


This mixed sediment is noted on several borehole data as a sandy clay. The thickness of the clay unit range between $2.8-18.2 \mathrm{~m}$ with an average value of $8.4 \mathrm{~m}$ (Fig.3). The third geoelectric layer consists of finemedium-coarse sand with intercalations of thin black plastic clays. This layer constitutes the aquiferous horizon. This layer is the prolific aquifer tapped by many productive water boreholes drilled in the area This layer is characterised by a range of resistivity values that range from 136.1-828.6 $\Omega \mathrm{m}$. High resistivities (e.g., over $90 \Omega \mathrm{m}$ ) probably indicate a fairly clean (clay-free) sand (Ayers, 1989). An average resistivity for this layer is about $350.6 \Omega \mathrm{m}$. It is worth noting that the aquifer exhibits variable thickness $(8.3-97.6 \mathrm{~m})$ and exists at different depths from site to site. 


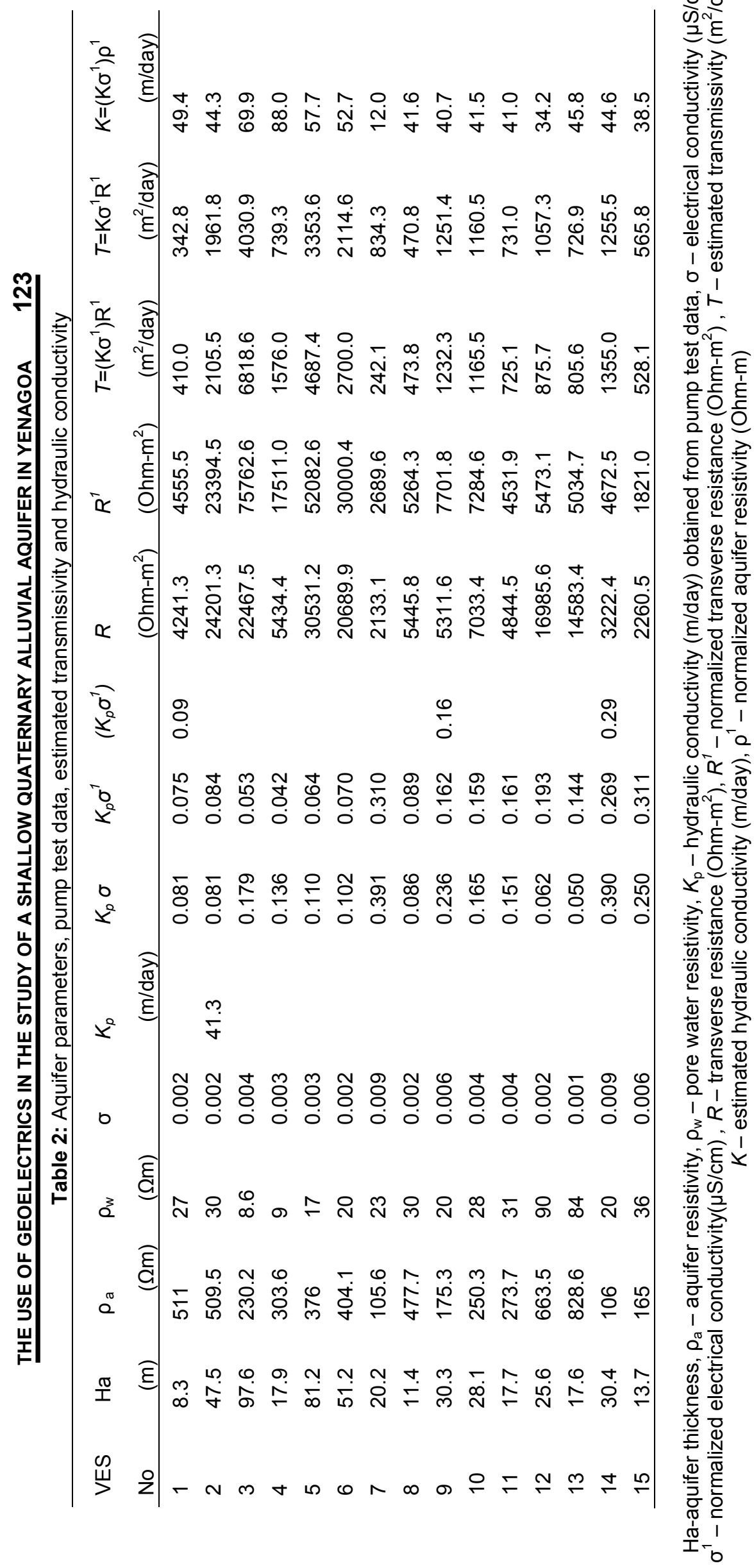


On the basis of $K \sigma^{1}$ values, the entire study area can be divided into three distinct zones (Table 2) with respective $K \sigma^{1}$ values equal to $0.09,0.16$ and 0.29 . The estimated transmissivity values are high over the entire area, with values ranging from $342.8 \mathrm{~m}^{2} /$ day in the vicinity of VES 1 to $4030.9 \mathrm{~m}^{2} /$ day estimated at VES 3 . These results are in agreement with the findings of Amajor (1991) in the study area using pump test data. The obtained transmissivity values are also consistent with the aquifer being unconsolidated with fine-mediumcoarse sands (Mbonu et al 1991). The results show that areas underlain by relatively thick aquifer materials have higher transmissivity values than areas underlain by relatively thin aquifer materials. This relationship is expected because transmissivity is a function of aquifer thickness, since hydraulic conductivity is assumed to be constant.

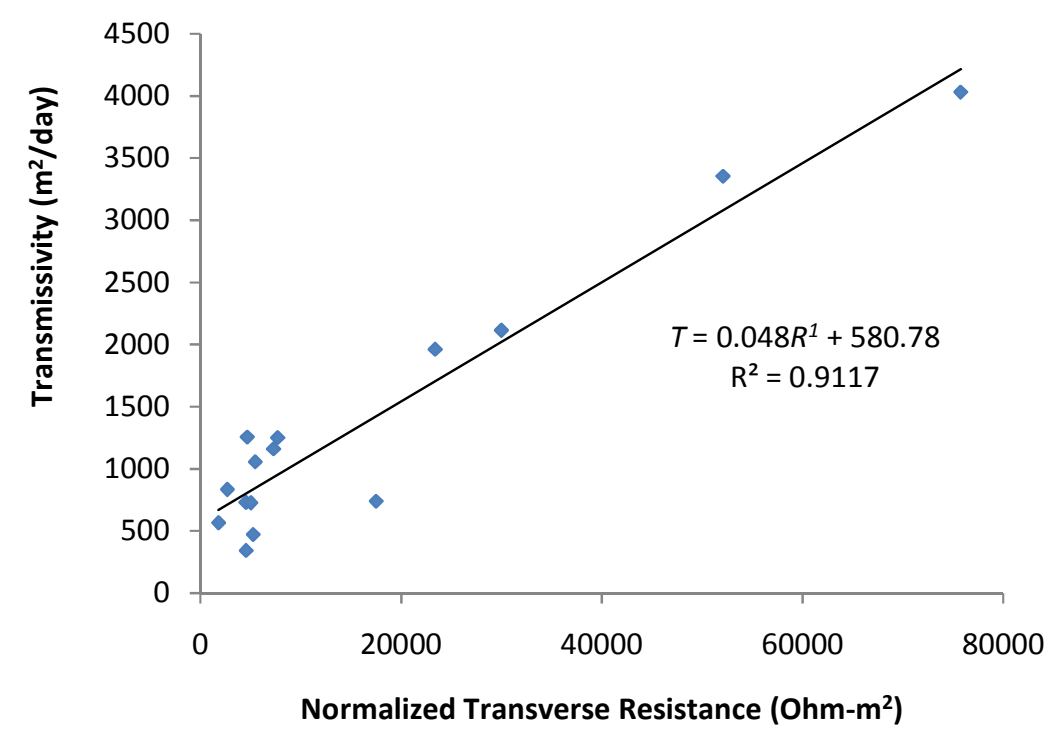

Fig. 4. Relationship between transmissivitty and normalized transverse resistance

The relationship between transmissivity and normalized transverse resistance is shown in Fig. 4. This plot shows the dependence of transmissivity with normalized transverse $\left(R^{1}\right)$ resistance as

$T=0.048 R^{1}+580.9\left(R^{2}=0.91\right)$

The slope of the line is positive which indicates the increase in $T$ with an increase in $R^{1}$ is in agreement with the earlier work done by Frohlich and Kelly (1985). Transverse resistance of any subsurface geological formation is given by the product of resistivity and thickness. A geological formation reflecting a predominantly high transverse resistance values indicates that its resistivity is high or it has higher thickness with favourable aquifer conditions. The aquifer in the study area reflects high transverse resistance so it has high transmissivity with good groundwater potential.

The hydraulic conductivities range from 12.0 to $88.0 \mathrm{~m} /$ day (Table 2). It is important to note that the calculated hydraulic conductivity $(K)$ value at VES station $2(44.3 \mathrm{~m} /$ day $)$ is identical to the value $(41.3$ $\mathrm{m} /$ day) obtained from the pump test at that vicinity. The relationship between hydraulic conductivity and normalized aquifer resistivity is shown in Fig. 5 . 


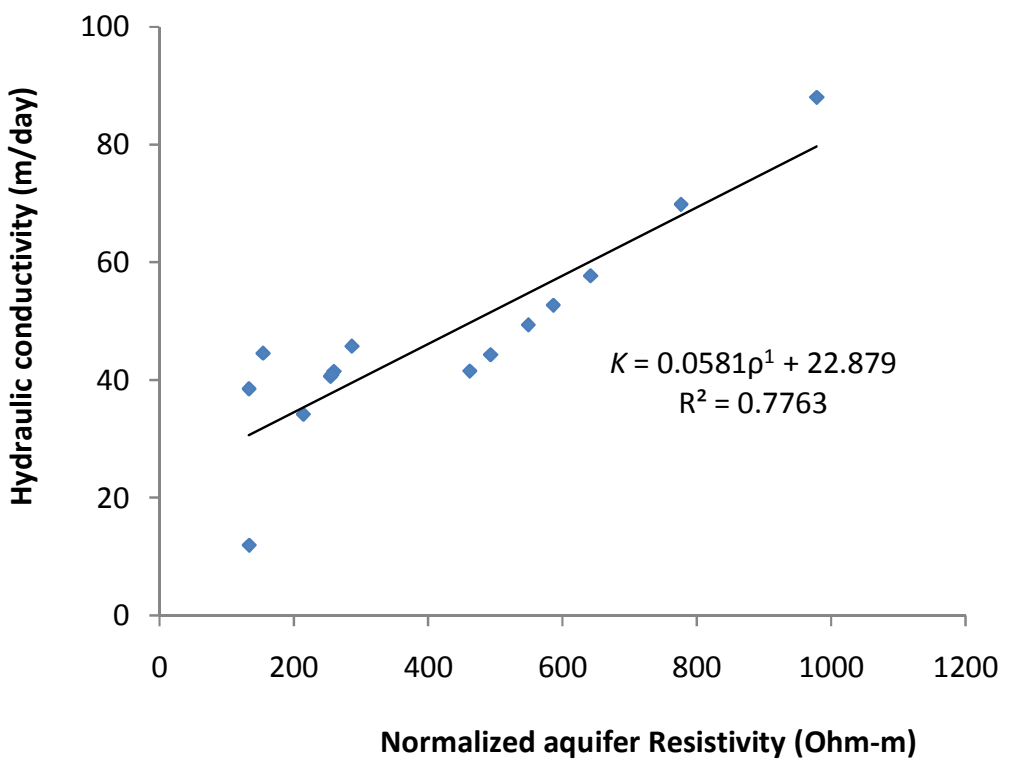

Fig. 5. Relationship between Hydraulic conductivity and normalized aquifer resistivity

The direct relationship between aquifer transmissivity and normalized transverse resistance of the alluvial aquifer system with varying water quality is quite meaningful and can be utilized for the estimation of transmissivity from resistivity data at other sites. The hydraulic conductivity at a location may also be estimated from the relevant equation, if the parameter $\alpha$ $=K \sigma^{1}$ is known for a reference well in the area. The strength of this method is the possibility for estimation of hydraulic parameters, thereby reducing the additional expenditure of carrying out pumping tests.

\section{CONCLUSION}

Results from geoelectric survey within Yenagoa metropolis and environs provided valuable information on the alluvial deposit and hydrogeologic framework of the alluvial aquifer. The results of the interpretation revealed three distinct geoelectric layers. These layers are (1) a relatively thin surface layer of fine grained material (top soil, silt or clay) with variable moisture content (2) a low resistivity layer, representing the near surface clay unit, and (3) a layer of fine-medium-coarse sand comprising the aquifer. The results of geoelectrical sounding conducted in the close vicinity of a borehole were used for establishing empirical relationships between the hydraulic and geoelectric parameters. The transmssivity correlated linearly with the normalized transverse resistance and hydraulic conductivity also linearly correlated with normalized aquifer resistivity. Transmissivity values in the aquifer vary from 342.8 to $4030.9 \mathrm{~m}^{2} /$ day, and hydraulic conductivity $K$ varies from $12.0-88.0 \mathrm{~m} /$ day throughout the study area.

\section{ACKNOWLEDGEMENTS}

The authors would like to express their sincere thanks and deep appreciation to the Post-graduate students of Exploration Geophysics in the Department of Physics, Niger Delta University, Wilberforce Island, Bayelsa State.

\section{REFERENCES}

Amajor, L. C., 1991. Aquifers in the Benin Formation (Miocene - Recent), Eastern Niger Delta , Nigeria. Lithostratigraphy, Hydraulics and water quality. Environmental Geology \& Water Science, 17 (2): 85 - 101.

Allen, J. R. L., 1965. Late Quaternary Niger Delta and Adjacent Areas: Sedimentary environments and lithofacies. Bulletin of American Association of Petroleum Geology. 49: 547 - 600.

Ayers, J. F. 1989. Consumptive use of geophysical and geological data in the study of an alluvial aquifer. Ground water, 27 (5): 625-632.

Frohlick, R. K. and Kelly, W.E., 1985. The relation between hydraulic transmissivity and transverse resistance in a complicated aquifer of glacial outwash deposits. Journal of Hydrology, 79: 215-229.

Frohlich, R. K. and Urish, D. W., 2002. The use of geoelectrics and test wells for the assessment of groundwater quality of a coastal industrial site. Journal of Applied Geophysics. 50: 261 278.

Kosinski, W. K. and Kelly, W.E., 1981. Geoelectric soundings for predicting aquifer properties. Groundwater, 19, (2): 163-171.

Louis, L, Karantonis, G, Voulgaris, N. and Louis, F., 2004. Geophysical methods in the determination of aquifer parameters: the case of Momos river delta, Greece. Res J Chem Environ., 18, (4): 4149.

Maillet, R., 1947. The fundamental equations of electrical prospecting. Geophysics, 3: 529-556. 
Mbonu, P.D.C, Ebeniro, J.O, Ofoegbu, C.O. and Ekine, A.S., 1991. Geoelectric sounding for the determination of aquifer characteristics in parts of Umuahia area of Nigeria. Geophysics, 56: 284-291.

Niwas, S. and Singhal, D.C., 1981. Estimation of aquifer transmissvity from Dar-Zarrouk parameters in a porous media. Journal of Hydrology, 50: 393399.

Niwas, S. and Singhal, D.C., 1985. Aquifer transmissivity of porous media from resistivity data. Journal of Hydrology, 82: 143-153.

Okiongbo, K. S. and Douglas, R. K., 2013. Hydrogeochemical analysis and evaluation of groundwater quality in Yenagoa City and environs, Southern Nigeria. Ife Journal of Science. 15: 209 - 222.
Short, K. C. and Stauble, A. J., 1967. Outline of the geology of the Niger Delta. Bull. AAPG. 51:761779.

World Health Organisation., 2004. Guidelines for drinking water quality: incorporating $1^{\text {st }}$ and $2^{\text {nd }}$ vol. 1 recommendations $3^{\text {rd }}$ ed., Geneva. 